\title{
IMAGINARIO EMOCIONAL DE LA VIOLENCIA EN NARRATIVAS COLOMBIANAS RECIENTES
}

\author{
Orfa Kelita Vanegas $V$. \\ Universidad del Tolima \\ Tolima, Colombia \\ okvanegasv@ut.edu.co
}

\section{RESUMEN / ABSTRACT}

En un conjunto de novelas colombianas de reciente publicación, lo emocional surge con fuerza protagónica para significar la realidad intangible derivada de la violencia política. Los escritores que abordamos retoman preocupaciones recurrentes de la literatura colombiana (la guerra, la humillación, la derrota, etc.), para tratarlas desde el filtro de lo afectivo y presentar otra lógica de lo violento. Lo afectivo, como elemento literario, permite no solo la exploración estética del estado anímico del sujeto que ha vivido en contextos traumáticos, sino también una aproximación a la violencia que vaya más allá de la lógica de sus causas, victimarios y efectos materiales, aspectos que han tenido mayor visibilidad en los textos y discursos. Narrar desde lo afectivo la realidad caótica de un país, da cuenta de un imaginario emocional de la violencia y del impacto que ha surtido en la identidad social.

PALABRAS ClAVE: emociones políticas, novela colombiana, violencia, trauma, identidad social.

\section{EMOTIONAL IMAGERY OF VIOLENCE IN RECENT COLOMBIAN NARRATIVES}

In a set of recently published Colombian novels the emotional arises as a protagonist force to signify the intangible reality derived from political violence. The writers that we approach resume recurrent concerns of Colombian literature (war, humiliation, defeat, etc.), to treat them from the filter of the affective and show another logic of the violent. The affective, as a literary element, allows not only the aesthetic exploration of the mood of the subject who has lived in traumatic contexts, but also an approach to violence that goes beyond the logic of its causes, perpetrators and material effects, aspects that have had greater visibility in the texts and speeches. Narrating the chaotic reality of a country from the affective field permits to visualize the emotional imaginary of violence and its impact on social identity.

KEYWords: Political emotions, Colombian novel, violence, trauma, social identity. 


\section{EMOCIONALIDAD TEXTUAL Y VIOLENCIA}

Lo emocional es una respuesta psíquica, íntima, tradicionalmente pensada como especie de "energía nomádica" que atraviesa los cuerpos y que está privada de razón". Sin embargo, ya Baruch Spinoza en "Ética demostrada según el orden geométrico" (1677), se refiere a las emociones como "ideas confusas" que, dependiendo del marco moral y social en el que se producen, afectan al sujeto en diversos grados de intensidad y de variadas maneras. La respuesta afectiva, entendida como idea, se anuda al estar cultural de la persona. Hablar de emociones como lo hace Spinoza es relativizar su rasgo natural, preconsciente y biológico, y rescatar a la vez su ambigüedad cultural y semántica. Sara Ahmed explica lo emocional como fenómeno que solo toma sentido si se relaciona con la experiencia previa. El dolor íntimo a causa de una experiencia traumática, por caso, es indicativo de impresiones pasadas, así no se esté totalmente consciente de ello. Aunque puede existir cierto grado de inconsciencia en la experiencia de los afectos, estos en sí mismos están mediados por vivencias anteriores que influyen en su reconocimiento (55). Por su parte, Martha Nussbaum correlaciona la emoción con el recuerdo y la memoria. Los afectos pasan por el tamiz de la tradición y la cultura para habituarse a los intereses individuales y de la comunidad en la que se ha crecido. Toda respuesta emocional afecta la lógica del orden social y está mediada por la razón, es condición que fortalece o erosiona los lazos comunitarios y genera la ilusión de una identidad colectiva (379-382). Estas observaciones sobre la complejidad de lo emocional, servirán en este artículo como punto de partida para reflexionar sobre los modos como parte de la narrativa colombiana de reciente publicación, articula desde una vasta red de emociones la violencia sociopolítica, abriendo con ello nuevas rutas de comprensión de la realidad social del país.

\footnotetext{
Una de las líneas de reflexión más relevantes en torno a las emociones y el llamado "Giro afectivo", nombra como afecto toda respuesta sentimental del ser humano a estímulos del mundo real. Esta mirada rechaza cualquier elemento cognitivo, racional o cultural en esa respuesta; la manifestación emocional, o afectiva, es producto de una fuerza instintiva, de una energía abstracta que circula entre los cuerpos, los atraviesa y sigue su curso. Una mera intensificación del cuerpo. Se ignora, en este enfoque, el carácter sobredeterminado de los procesos corporales. Para profundizar en el tema, remitirse a Parables for the Virtual: Movement, Affect, Sensation (2000), de Brian Massumi; "El afecto y la poshegemonía" (2008), de Beasley-Murray, y El lenguaje de las emociones. Afecto y cultura en América Latina, de Mabel Moraña e Ignacio M. Sánchez Prado (2012).
} 
En los últimos años numerosos estudios han ido revalorizando lo emocional como elemento notable para entender no solo lo inefable, sino también las estructuras sociales básicas que conforman la vida cotidiana del sujeto contemporáneo. Las texturas sentimentales se muestran más interesantes que los textos, los discursos y los archivos, para indagar la realidad en sus diversos vocabularios y simbolismos. El estudio de las emociones viene imponiéndose sobre el análisis de las razones (Bartra 20). Esta revitalización de lo emocional se ancla a situaciones socioculturales, procesos trasnacionales y locales, enlazados a las dinámicas de la globalización. Las relaciones de fuerza que dan orden al ámbito internacional contemporáneo delimitan nuevos procesos de construcción de subjetividades e imaginarios colectivos. Circunstancias como la alteración de los modos de vida a causa del desplazamiento, la migración y el exilio, o el incremento de la violencia asociada al terrorismo internacional, el narcotráfico y la trata de personas "ponen sobre el tapete el factor del afecto como un nivel ineludible para el estudio de las formas con frecuencia inorgánicas y discontinuas a partir de las cuales se manifiesta y expresa lo social" (Moraña, El lenguaje 314).

En Latinoamérica, la escalada de la violencia, en sus múltiples expresiones, genera climas de miedo que envuelven al ciudadano en una sensación de constante amenaza, y motiva sentimientos de fracaso, apatía, resentimiento, entre otros. Esta realidad viene reclamando nuevos vocabularios que nombren lo intangible de su naturaleza, pues el lenguaje que tradicionalmente ha definido lo violento tiende a priorizar las causas concretas, el contexto histórico y sus directos responsables, dejando de lado el impacto afectivo de la víctima (Cavarero, Butler). Sobre esta situación, Sofsky tiene razón al advertir que el lenguaje enfocado en los agentes y el conflicto impide el acceso a la verdad de la violencia, es sordo y ciego para el suplicio de las víctimas (65). Entender lo que nos sucede hoy como sociedad necesita de la exploración de la respuesta psíquico-afectiva de quien sufre el impacto de la violencia. El gesto emocional apunta hacia los modos como se constituyen hoy los imaginarios sociales. De esta manera, parte de la novelística en Colombia, paulatinamente, viene representando los afectos como estrategia para indagar la identidad emocional de una sociedad signada por prácticas atroces de poder. La narrativa, al correr en relativo paralelismo con las dinámicas sociales, "sitúa la mirada de la violencia en un punto de permeabilidad constante entre los sucesos violentos y la forma como éstos van siendo entendidos y narrados" (Rueda 9). 
Escribir sobre violencia política no es nada nuevo en la literatura colombiana. Las diversas manifestaciones de violencia, sus causas y efectos, han sido siempre fuente de inspiración para los escritores nacionales. Ubicada en la realidad caótica, la narrativa reinterpreta el pasado, da forma a otras verdades para explicar el presente y recuperar las memorias que han sido opacadas por el discurso oficial. Asimismo, ante la necesidad de indagar las múltiples facetas de la violencia, el campo literario permanece en continua exploración de recursos estéticos e invención de lenguajes. El devenir del país, en este sentido, es detonante poderoso del quehacer del escritor. El narrador de Los derrotados, alter ego del autor, frente a los procesos de lo literario en Colombia, deduce:

Las mejores obras de nuestra literatura, o al menos las más representativas, son el recuento de una hecatombe colectiva que sucede en las selvas, la saga sangrienta así haya resplandores mágicos de una familia de frustrados, el nihilismo de alguien que denuncia con irreverencia la sociedad criminal en que ha nacido [...] Y si no es la violencia de lo que se debe escribir, sale al paso su consecuencia inevitable: la humillación, la vergüenza, la derrota (Montoya 145).

Los textos elegidos para este ensayo nuevamente recurren a la violencia y sus variantes. Pero esta vez, la escritura se articula al lenguaje de las emociones para explorar de renovada manera las consecuencias íntimas de la violencia en el seno social. Desde la afectividad del personaje-sufriente la historia del trauma político adquiere otros sentidos. Se reconoce que a partir de la década de los sesenta del siglo pasado, la narrativa nacional empezó a representar los conflictos bélicos, tomando como eje las consecuencias anímicas que éstos dejan en la sociedad y el sujeto. De un primer momento, que se detuvo en significar la violencia contando los actos materiales más crudos, se pasó a la valorización de su huella psicosocial. Desde esa época, el reto de los escritores colombianos ha sido el de no sacrificar el valor estético en aras de figurar minuciosamente la crueldad con que se cometen los crímenes más atroces. García Márquez fue uno de los primeros en señalar que "la novela no estaba en los muertos de tripas sacadas, sino en los vivos que debieron sudar hielo en su escondite" (12). Es decir, que la riqueza -estética, cultural, políticadel drama literario se centra en la recreación del ambiente emocional, que se desprende del escenario del crimen.

No obstante, ese primer giro de la novela hacia la valorización literaria de los efectos íntimos, pese a que matizó la descripción de escenas dantescas, 
siguió enfocando con mayor luz las causas del conflicto y a sus directos responsables. Esto es, que la orientación narrativa seguía más interesada en develar la posición crítica-y muchas veces política-de los actores concretos de la violencia, que en visualizar el impacto intangible, el aspecto emocional de quien la sufre directamente, especialmente de aquellos que no participan de las contiendas, que, incluso, permanecen ajenos a inclinaciones ideológicas. La obra de García Márquez es representativa de este enfoque: El coronel no tiene quien le escriba y La mala hora, en concreto.

Suele aceptarse que los escritores más contemporáneos han fijado la atención en las prácticas estéticas de sus antecesores. No obstante, la representación de los efectos de la violencia se configuran ahora a partir de lo emocional traumático más íntimo: el dolor, la desdicha, el horror, entre otros. En novelas de reciente publicación, las emociones emergen con poder protagónico, significan lo puramente afectivo de quien es avasallado por la guerra o el hecho atroz. Los elementos ficcionales -tiempo, lugares, tema, personajes- adquieren densidad gracias a la intimidad perturbada de quien narra. Sin dejar de lado la alusión a elementos socio-históricos, que sugieren al lector las causas del conflicto, varios escritores vienen mostrando un marcado interés por nombrar la sensibilidad herida, por dar forma a la particularidad emocional del ciudadano común, que sin ser parte activa de la guerra y demás violencias, se ve arrasado por estas. Los escritores colombianos elegidos para este estudio van al lugar de los afectos lesionados para luego regresar y contar lo que hay en ellos. Lo emocional es el lugar donde la novela logra llegar para descubrir una de las zonas más enigmáticas y ocultas de lo humano, en su condición individual y social.

\section{LA REALIDAD EMOCIONAL DE LA VIOLENCIA EN LA FICCIÓN}

Dentro del conjunto de textos que viene explorando el lenguaje de las emociones como espacio para situar otros ángulos de indagación de la violencia, prevalecen aquellos que problematizan el mundo del narcotráfico. La manifestación psíquico-afectiva de quien padece, directa o indirectamente, las prácticas criminales derivadas del negocio de la droga, toma especial simbolismo en narrativas publicadas en años recientes. Estas propuestas se caracterizan por trascender lo anecdótico y no dar ya centralidad a la descripción de actos atroces, ni al papel de sus figuras representativas: narcotraficantes y sicarios. Sobresalen, más bien, las consecuencias psíquicas y emocionales de ese flagelo. 
El miedo, la desesperanza y el resentimiento son agentes que movilizan la ficción. De hecho, elementos como el impacto cultural y la configuración territorial de la ciudad a raíz de la criminalidad del narcotráfico - que fue en su momento tema central de ficciones icónicas como La virgen de los sicarios y Rosario Tijeras- aparecen ahora como "telón de fondo" o se referencian de manera tangencial.

Delirio, de Laura Restrepo, es una de las primeras ficciones nacionales que indaga el elemento psíquico-afectivo derivado de la violencia del narcotráfico. La escritora inventa una zona de tensión entre personajes de diferente índole, simbólicos de la respuesta emocional de la sociedad colombiana al poder devastador del negocio de la droga. Por su representación explícita de la enfermedad psíquica, el delirio, la novela ha sido objeto de estudio no solo desde el eje histórico y sociológico, sino también en relación con conceptos del campo del psicoanálisis, lo fenoménico y lo axiológico. La propuesta de escritura de Restrepo reordena la red emocional de la sociedad de los años ochenta del siglo pasado, que fue la década en que el narcotráfico golpeó al país con mayor fuerza. El delirio se figura como "síntoma sensitivo que explica el desorden sensorial de la realidad" (Blanco 12). Desde la perspectiva de Jaramillo Morales, la narración de la autora colombiana es un recorrido de la elaboración del dolor íntimo, para remediar en algo el estado melancólico de la sociedad. La escritura, desde esta perspectiva, conduce al recobro de las "memorias sepultadas" (130), para dar forma a un pasado nefasto y conducir con ello a cierta redención.

La figuración del delirio como estado íntimo traumático derivado de la violencia correlaciona a su vez una gama de emociones de rasgo político, es decir, de afectos que intervienen directamente en la conformación de la sociedad y condicionan los imaginarios culturales (Robin, Nussbaum, Ahmed). Bajo este ángulo, la historia de Midas McLister, narrador central de Delirio, toma importancia porque a través de sus andanzas se registran las emociones públicas derivadas de la confrontación social y económica entre ricos y pobres. Se recordará que tal personaje es el enlace entre los estratos sociales del país: de familia humilde pasa a posicionarse en la clase alta gracias al lavado del dinero del narcotráfico. Para Suárez, uno de los mayores aciertos de la novela de Restrepo es "la tensión que crea McLister y su función acusadora de la inversión de valores resultado del narcotráfico" (115). La narración se sirve de este protagonista para denunciar el anquilosado paradigma social de inclusión/exclusión que la economía del narcotráfico fue incapaz de solventar y de la cual, por el contrario, agudizó sus diferencias y 
fomentó una cultura de la apariencia y la ostentación. Dice la ensayista, que McLister le recrimina a Agustina, figura representativa de la burguesía, que la "diferencia infranqueable" entre su mundo y el de él es únicamente "la apariencia y el brillo externo", le reprocha también que su familia lo trate como un "sultán" por su posición de nuevo rico, y le señala, además, la doble moral de sus parientes que han roto todas sus bien cuidadas convenciones para aceptar su lavado de dinero del narcotráfico (115).

Con Suárez estamos de acuerdo en el notable papel que McLister juega en la novela para retratar la doble moral de la sociedad colombiana frente al negocio de la droga, también consideramos acertadas sus reflexiones sobre la capacidad de la escritura de Restrepo, para escenificar los estragos causados por el narcotráfico en el tejido social; no obstante, somos de la opinión de que Midas McLister no se ufana de su papel de "nuevo rico" y de su posicionamiento en la burguesía bogotana. En el presente de la narración el héroe con "el dolor [del] alma" acepta que se equivocó (Restrepo 136). Sabe que cometió el error de creer que el contraste entre ricos y pobres era solo "cuestión de empaque", de "brillo externo" (182). Midas entiende que pese a su riqueza material, nunca fue parte del mundo de la familia de Agustina. Los ricos solo lo reconocen en la medida en que facilita los negocios con Pablo Escobar, nunca ven en McLister a alguien de su rango y mucho menos a un amigo. Esta situación le genera al personaje gran desdicha. En una especie de autoconfesión expresa: "ante mi se arrodillan y me la maman porque si no fuera por mí estarían quebrados, con sus haciendas que no producen nada [...] Pero eso no quiere decir que me vean. Me la maman pero no me ven" (Restrepo 137). La voz remarca en la profunda desazón íntima que produce saberse menospreciado por carecer de linaje y "verdadero" estatus social.

Con McLister, la escritura de Restrepo propone la formación emocional de un sujeto en un mundo donde el valor de la persona depende del abolengo y el dinero: “¿Alcanzas a entender el malestar de tripas y las debilidades de carácter que a un tipo como yo le impone no tener nada de eso, y saber que esa carencia suya no la olvidan nunca aquéllos, los de ropón almidonado por las monjas Carmelitas?" (Restrepo 137). Remarcar sobre la carencia produce una sensibilidad resentida, que acusa las formas discriminativas del engranaje social. La anulación del otro como persona a causa de su desfavorable origen se suma a los actos de injusticia y cultiva sentimientos de rencor y frustración. A medida que el lector se va enterando de las estratagemas ilegales de McLister para trepar socialmente, asiste también al develamiento de las hondas disparidades en la calidad de vida de una sociedad fuertemente 
estratificada. El poder, el dinero y el prestigio social que en determinado momento Midas logra tener, paradójicamente, no hace sino recordarle su condición de desamparo y segregación.

Pese a que "conquista" una posición económica, el personaje sigue sintiéndose excluido, situación que le empuja a una estimación más baja de sí mismo y a sentir un profundo rencor. Por esta razón, cuando al final se queda solo y sin dinero, Midas McLister se siente víctima, pero no tanto de la persecución de los jeques de la droga y de sus propios equívocos, sino más bien de la clase privilegiada del país, que ennoblece a unos cuantos y fija límites más allá de los cuales siempre queda alguien en condición de excluido. La precisión y el tono irónico con el que el héroe cuenta su propia vida exterioriza una sensibilidad abatida, que reconoce que ha perdido la jugada contra una sociedad esnobista y mentirosa. El desenmascaramiento del rostro falaz de la burguesía bogotana y de sus devaneos con el narcotráfico se hace a través de la emocionalidad de McLister, del profundo resentimiento que le despiertan aquellos en los que confió y que luego le abandonaron. En este orden de argumentos, podemos decir, que lo afectivo se construye en la ficción como el intersticio en el cual los procesos de subjetivación, derivados del orden social y del impacto íntimo del narcotráfico, se revelan y logran tener representación.

Inequidad, desprecio y desdicha, son términos por los que también transitan los personajes de Plegarias nocturnas. La novela de Santiago Gamboa representa el panorama de una sociedad sacudida por los revuelos políticos de la primera década del siglo XXI en Colombia. Manuel, joven filósofo, narra su pasado mientras está prisionero en una cárcel de Bangkok, esperando la pena máxima: acusado, sin serlo, de traficante de drogas. Sabemos que este personaje abandona el país con la idea de reunirse en Japón con su hermana, quien había migrado dos años atrás a causa de la amenaza de un grupo criminal asociado con instituciones del Estado. Empero, la otra razón por la que Manuel se va, es el repudio hacia la realidad opresiva que atravesaba tanto a su familia como a la sociedad en general:

éramos parte de algo oscuro, triste, que ninguno [...] podría ya cambiar. El aroma de loción barata, el brillador de suelos, el perfume de gabardinas y chaquetas, no lo sé. El intenso olor de una familia humillada, que creía merecer una segunda oportunidad, sin jamás tenerla [...] Siempre odié lo que define la vida en ese lugar: el arribismo, el afán de figurar, el odio, la tacañería congénita, la envidia [...] ;la época más horripilante! Un presidente mafioso, un ejército asesino 
y torturador, medio Congreso en la cárcel por complicidad con los paracos, más desplazados que en Liberia o Zaire, millones de hectáreas robadas a bala $[\ldots]$ este país se sostiene a punta de masacres y fosas comunes (Gamboa 20,65).

El momento histórico que Gamboa escenifica se corresponde con los dos periodos de gobierno de Álvaro Uribe Vélez, 2002-2006 y 2006-2010, años cruentos disfrazados de progreso económico y políticas de seguridad democrática. Desde la perspectiva del politólogo Miguel Herrera Zgaib, durante esa etapa presidencial, Colombia fue dirigida con una especie de fórmula de gobernabilidad legal (no) democrática, un régimen para-presidencial que se concretó en el proyecto regionalizado de la para-república bajo control de las autodefensas desmovilizadas con la "Ley de justicia y paz", cuyos jefes, no sobra decir, fueron extraditados por narcotráfico. El investigador colombiano caracteriza este periodo como la "(de)generación democrática de Colombia" (253), en la que se validó la política de guerra en la opinión pública.

El modo como las circunstancias más crudas del país entran en Plegarias nocturnas y atraviesan la vida afectiva de los personajes da consistencia a la realidad impalpable y crea un espacio epistémico para las emociones. El recurso literario consiste en ubicar a los héroes en situaciones históricas precisas, como el caso de los Falsos positivos ${ }^{2}$, para narrar emocionalmente los acontecimientos (Gamboa 211). Este artilugio genera en el lector cierta ilusión de veracidad sobre lo que se cuenta, efecto que a su vez da mayor peso a la contestación de la situación social y política que la escritura persigue. El disgusto hacia el estado de cosas en el país se traza en la novela como gesto emocional que simboliza la desilusión ante el futuro y el quiebre de la esperanza de proyectos alternativos optimistas. La narración se diseña a modo de queja. Es una descarga de indignación contra un Sistema que frustra las aspiraciones e infunde en la población más joven una sensación de vacío de futuro.

La escritura de Gamboa representa la realidad del país a partir de una violencia no siempre visible y mediatizada. En entrevista con Albinson Linares el autor expresa su preferencia por dejar de lado los factores más

2 Ejecuciones extrajudiciales cometidas por unidades militares de las Fuerzas Armadas de Colombia. Las víctimas eran asesinadas por soldados para obtener ganancias personales, pues el Gobierno reconocía económica y simbólicamente a los comandos que más guerrilleros dieran "de baja". 
conocidos de la violencia en Colombia -el tráfico de drogas, las guerrillas y los paramilitares-, para visibilizar con mayor fuerza los sucesos traumáticos individuales, que se derivan de esa otra "gran violencia" y, asimismo, socaban el equilibrio de la vida social y cotidiana ${ }^{3}$. De esta manera, Plegarias nocturnas, aun cuando relaciona en su trama los desafueros criminales de un gobierno y sus vínculos con organizaciones ilegales, presta mayor atención a la realidad mustia que empaña la vida de los personajes, conduciéndolos al desamparo y el suicidio. La ubicación en la novela de dos espacios de violencia, uno nacional y otro familiar, aunque coligados entre sí, identifica lo emocional como elemento articulador de la vida social y el universo personal. Manuel, al referir situaciones concretas de confrontación con sus padres y hermana, transforma el conflicto con su entorno familiar y la lucha continua contra sí mismo, en experiencia anímica social. En este sentido, el espacio privado se construye en la escritura a modo de topos-afectivo, simbólico de los grandes estados anímicos de la contemporaneidad nacional e internacional. La narración del lugar personal trasciende en espacio potencialmente emocional para significar el síntoma de la crisis de porvenir y del sentimiento de intrascendencia, que se viene reproduciendo en diversas sociedades desde finales de los setenta, a raíz de la fractura de las utopías modernas y de la degeneración política. Un estado de cosas que tiende a agravarse en contextos tan caóticos como el colombiano y que impacta con mayor brutalidad, en el universo emocional del sujeto y la sociedad.

El malestar hacia una época nacional en la que la vida personal y social parecía invivible, es también motivo de escritura para Juan Gabriel Vásquez. El ruido de las cosas al caer es la exploración de los estragos íntimos causados por el narcotráfico en la sociedad colombiana. A diferencia de Restrepo, que enfoca el delirio como estado psico-afectivo para desenmascarar otras verdades de la realidad del país, Vásquez centra la atención en el miedo. Esta emoción es el elemento en torno al cual la narración rastrea el efecto

3 Recuérdese, por ejemplo, que Perder es cuestión de método (1997) se articula en torno a la investigación del asesinato de un hombre anónimo. Situación "aislada" que lleva al protagonista por diversas rutas de indagación que van revelando las violencias más visibles, aquellas generadas del contrabando, el crimen y la corrupción política. Por su parte, El sindrome de Ulises (2005), concentra la atención en la lucha por la supervivencia de los exiliados pobres en París. Nuevamente, la trama se ancla a situaciones traumáticas particulares para reflejar a su vez situaciones de índole social y político: los indocumentados, la pobreza y los inmigrantes desamparados en las grandes urbes del "Primer mundo". 
anímico del narcoterrorismo en la esfera pública. La escritura da forma a la sensibilidad de la generación nacida en la década de los setenta y que vivió su juventud temprana durante los conmocionados años ochenta -periodo al que pertenece tanto el escritor como su narrador protagonista-.

Al inicio de la novela, de manera intempestiva, brota en Antonio Yammara el pasado como un espectro, lo acosan las bruscas invasiones de un episodio de su vida que creía cerrado, pero que resurge a causa de una imagen publicada en una revista. La evocación involuntaria se filtra en el presente del personaje obligándolo a desandar lo vivido, a fusionar el "orden afectivo" con el "orden intelectual" de la memoria, en el sentido de que cada retazo de recuerdo, conservado u olvidado a capricho de la emoción íntima, toma forma y densidad cuando el narrador decide reconstruirlo con palabras ${ }^{4}$. En el registro de un pasado, que comprometió la vida social del país, el héroe de Vásquez rehace uno de los momentos más dolorosos de su juventud temprana, cuenta su lucha por salir del estado de horror y desamparo a causa de un atentado homicida dirigido a un amigo, pero en el que él también salió gravemente herido. A partir de este suceso ficcional, la escritura explora la emocionalidad traumática de la sociedad colombiana durante la década de los ochenta, años dominados por un clima de miedo a razón del narcoterrorismo. Este periodo se erige en la narrativa como espacio de confrontación entre la mirada externa de la violencia -los victimarios, las bombas, las estadísticas-y la percepción anímica -el dolor y la turbación-.

El texto cuenta una época en la que los más jóvenes se hicieron "temerosamente adulto[s] mientras a [su] alrededor la ciudad se hundía en el miedo y el ruido de los tiros y las bombas" (Vásquez 254). La inscripción literaria del miedo como elemento fundamental de la memoria compartida por una generación lo desborda de las fronteras de lo íntimo, de la sensibilidad individual, para transformarlo en fenómeno afectivo social. Como bien deduce Gaitán, la obra del escritor colombiano presenta una "radiografía del miedo", que hace lectura tanto de las causas del negocio de la droga como de "los desajustes emocionales que habrían de perdurar entre quienes alguna vez

$4 \quad$ En un estudio anterior de El ruido de las cosas al caer analizamos la incorporación estética de la fotografía en la trama narrativa. La novela se sirve de la imagen visual como recurso narrativo y motivo afectivo, para proyectar una nueva mirada del pasado reciente del país. La imagen en la novela establece un "acto de ver desobediente" que cuestiona la regulación visual y memorativa de los entes de poder-legales y de facto- sobre los modos violentos como se ha construido el país y los imaginarios de nación e identidad. 
fueron víctimas o vieron vulnerada su ciudad" (1). El miedo de Yammara, en consecuencia, solo puede comprenderse en relación con las circunstancias sociales y políticas que cercaron el devenir de una generación. Este modo de contar lo violento, de dar forma estética a lo inefable, recalibra el valor literario de las propuestas de escritura que tematizan la violencia del narcotráfico más allá de la descripción de escenas macabras. No es la escenificación de la expresión visible de la violencia -sicarios, narcotraficantes, destrozos materiales, torturas-, es lo íntimo muy propio lo que toma protagonismo en el relato para significar el elemento psíquico-afectivo de una sociedad en un momento histórico determinado.

Vásquez remarca tanto en el impacto momentáneo del miedo, es decir, en la conmoción que se produce en el instante inmediato de la amenaza, como en las secuelas psíquicas que perduran a lo largo de la vida. Han transcurrido cerca de quince años cuando el narrador se decide a contar el pasado que lo marcó de manera tan aciaga. Pese a que muchas de las impresiones de esos años terribles parecían haberse ido al olvido, la narración, desde el presente ficcional, arroja nueva luz sobre lo ocurrido y descubre que el miedo sigue permeando la realidad actual de Yammara.

La intención nemotécnica del relato no hace otra cosa que evidenciar cómo el miedo no se circunscribe únicamente al momento de la amenaza, sino que extiende sus tentáculos hacia espacios y tiempos insospechados. El miedo, se sabe, sigue latente en la rutina cotidiana de sociedades que ahora viven en relativa calma después de atravesar años de guerra. Es una emoción que socava silenciosamente la intimidad del habitante de las grandes urbes (Rotker, Martín Barbero), que prescribe, incluso, por varias generaciones los imaginarios culturales o de representación de la realidad. Este continuum emocional adverso es el que, paulatinamente, empieza a tomar significación cardinal en la novelística colombiana reciente.

Así como la propuesta de escritura de Juan Gabriel Vásquez explora la emocionalidad de la persona que ha sido blanco de un acto atroz, y el modo como esta experiencia deriva en alegoría de una sensibilidad de época, Evelio Rosero también propone un texto que hace del impacto emocional inmediato de la violencia, el núcleo de su narración. La novela titulada significativamente Los ejércitos, refleja con virtuosismo literario la vivencia cotidiana del terror sin acudir a la explicación de sus referentes políticos - mas dejando latente en el relato que estos son la causa-. El personaje narrador, un viejo profesor jubilado, cuenta los golpes diarios de la guerra a los que se ven sometidos tanto él como sus vecinos. Ismael, protagonista central, experimenta con 
alucinado terror la devastación de su pueblo a manos de unos "ejércitos anónimos". Estos ejércitos pueden ser del gobierno, de la guerrilla y de los paramilitares, pero la novela no hace distinción entre ellos porque "nada importan las diferencias entre los tres ejércitos para el anciano narrador y los habitantes de ese poblado, civiles víctimas de la impunidad, hundidos en el mayor de los desamparos" (Castellanos Moya 62-63). Para un sociólogo o especialista quizás sea evidente la confrontación por el poder, pero para un sujeto desamparado en medio del cruce armado resulta imposible e incluso intrascendente entender cómo funciona la dinámica militar que lo arrasa. Por esta razón, en la realidad ficcional los bandidos "son todos [Estado constitucional y Estado de facto] pues afectan del mismo modo al ciudadano, que no reconoce el conflicto como suyo sino en tanto lo padece" (Hoyos 285). Con Rosero, la escritura del miedo, que a momentos se transforma en estado de horror puro, simboliza la insensatez de la guerra en Colombia, la crisis de la razón y la negación de todo discurso que pretende darle una lógica a la historia del conflicto. El lector se ubica ante un paisaje trágico, que le presenta "la intrincada penetración de la guerra en los meandros de la vida ordinaria y su capacidad asombrosa de minar las fronteras del yo" (Moraña, La escritura 195).

El tono íntimo y mesurado con el que el narrador cuenta su propio estado emocional devela una sensibilidad que parece habituada a convivir con el terror. "Rosero configura el estado mental [...] la manera como viven los colombianos la guerra" (Padilla Chasing 122). El miedo, en este sentido, es efecto no de una amenaza que surge de manera inesperada, sino de la suma de diversos momentos surcados por actos de violencia; es una especie de ambiente afectivo que se instala a lo largo del tiempo y el espacio. El testimonio personal de Ismael, "más que registrar datos de la realidad, cuenta la experiencia del horror" (Van Der Linde 189). Desde el comienzo de la narración nos enteramos de que la percepción del pasado, el presente y el destino del pueblo y sus habitantes está regida por las circunstancias violentas.

La experiencia del miedo abre historias pasadas de asociación cuando el narrador revive conmociones traumáticas de su juventud. De hecho, la novela toma forma a partir de esta lógica asociativa. La historia entre Ismael y Otilia es resultado de tal procedimiento narrativo. Recuérdese que el narrador rememora que cuando ve por primera vez en la terminal de buses a quien será su mujer, un hombre es asesinado, justo en ese momento y lugar. La pareja de esposos es testigo, a lo largo de sus años de convivencia, de la intensificación de la guerra, y en el presente de la realidad ficcional son 
víctimas directas por la desaparición de Otilia. Con ella desaparece también el pueblo mismo y la existencia propiamente humana del narrador. "El deterioro físico y mental [y emocional] de Ismael progresa al ritmo de la violencia creciente" (Van Der Linde 181). Al final de la novela, el narrador no es más que una presencia fantasmal tratando de conservar la memoria del país (Fonseca 163-174), que es justamente la memoria del dolor y el miedo. Lo emocional traumático derivado de la guerra, en consecuencia, deviene fenómeno articulado al recorrido existencial del héroe, es hilo que se teje a sus deseos y desesperanzas:

En la montaña de enfrente, a esta hora del amanecer, se ven como imperecederas las viviendas diseminadas, lejos una de otra, pero unidas en todo caso porque están y estarán siempre en la misma montaña, alta y azul. Hace años [...] me imaginaba viviendo en una de ellas el resto de la vida. Nadie las habita, hoy, o son muy pocas las habitadas; no hace más de dos años había cerca de noventa familias, y con la presencia de la guerra [...] solo permanecen unas dieciséis. Muchos murieron, los más debieron marcharse por fuerza: de aquí en adelante quién sabe cuántas familias irán a quedar, ¿quedaremos nosotros?, aparto mis ojos del paisaje porque por primera vez no lo soporto (Rosero 61).

La cita deja ver que la conmoción afectiva del personaje no puede entenderse sin relacionar su pasado personal, pero tampoco sin mencionar la historia de su propio pueblo. La angustia del narrador, no es solamente la recordación de proyectos particulares frustrados, es también la negociación con el tiempo histórico de la violencia política del país. Aunque narración de la experiencia individual de la violencia, el estado emocional de Ismael es también revelación de los afectos colectivos, del clima emocional de la sociedad. Rosero, en efecto, no da forma a emociones inocentes y casuales emanadas de la psiquis perturbada de un individuo, sino que ante todo personifica de modo notable, la sensibilidad de una sociedad socavada por décadas de violencia. La tentativa de la narración de dar voz a un estado emocional como el horror ${ }^{5}$

Son varios los estudios que tratan de descifrar la imposibilidad de la instancia narrativa de Los ejércitos, pues si se tiene en cuenta la realidad ficcional que persigue y aplasta al personaje que cuenta, desde una lógica no ficcional y punto de vista narratológico, es imposible que se pueda articular un discurso con la lucidez expresiva como la que se desarrolla a lo largo de toda la narración (Moraña, La escritura). Para entender esa imposibilidad del agente 
-que es junto al dolor uno de los fenómenos que con mayor contundencia se cierra a la posibilidad del lenguaje (Sofsky 65)-, explora de modo sugestivo "las conexiones entre sentimiento y conocimiento, subjetividad, empiria y discurso, realidades materiales y simbólicas, historia y ética" (Moraña, La escritura 193). En suma, la vindicación estética de lo afectivo, que no implica la cancelación del elemento racional, logra significar los diversos elementos del conflicto de manera más decisiva que si la novela estuviese atravesada por un discurso de país o manifiesto político.

La narrativa al involucrar las diversas maneras en que funciona la experiencia del miedo, ya sea en la cultura pública o en la vida cotidiana, se dispone como fuente de conocimiento que traduce los efectos derivados de la relación emocional de un colectivo. Tanto Rosero como Vásquez, con la representación del miedo ponen en juego una de las emociones más complejas y determinantes de los imaginarios de la sociedad nacional, y del mundo contemporáneo en general (Beasley-Murray, Robin, Nussbaum). La reconstrucción literaria de determinados momentos de la historia del país evidencia que el miedo ha sido originado y encausado por todo tipo de gobierno -oficial o de facto-, para controlar en su amplia gama existencial al colombiano, como individuo y ser social. La escritura, en este orden, se abre como posible camino para identificar cómo el miedo y sus variantes definen el funcionamiento social y el orden político.

Para cerrar este apartado, no sobra anotar que la narración emocional de la violencia comienza también a revisitar y reinterpretar la Historia nacional para contar desde la óptica del oprimido otra verdad. La propuesta de escritura de Miguel Torres es decisiva en este propósito. En El incendio de abril ${ }^{6}$, el enfoque de la violencia política se hace desde el dolor, la angustia y la desesperación de los capitalinos ante las circunstancias históricas que el país imponía. Los sucesos ficcionales giran en torno al miedo y la consternación de personas comunes que huyen del lugar del atentado y de quienes no encuentran a sus

narrativo que Rosero inventa, Buiting actualiza la idea del "narrador imposible" de Agamben. La autora sostiene que la imposibilidad de la narración y la inhumanidad experimentada y confrontada por el personaje narrador de Los ejércitos, están inextricablemente relacionadas, por tanto, las técnicas narrativas utilizadas por el autor colombiano se fusionan de manera estratégica, se logra la verosimilitud en la conjugación de los elementos ficcionales.

Esta es la segunda novela de la Trilogía el 9 de abril, que narra el Bogotazo: la barbarie desencadenada horas después del asesinato de Jorge Eliecer Gaitán, el 9 de abril de 1948. Las otras dos obras son El crimen del siglo (2006) y La invención del pasado (2016). 
seres queridos: desaparecidos durante la reyerta. El asesinato del caudillo aparece solo como escenario de fondo. No prima la idea de reubicar la memoria de Gaitán y valorizarlo como actor destacado de la historia política del país, es la presencia afectiva derivada de ese momento caótico lo que palpita en la palabra. Lo afectivo, en este orden, abre otros horizontes hacia la comprensión de las dinámicas sociales y la historia. Los nuevos contextos surgidos de la violencia extrema, la sobreexposición del dolor, el desencanto político, entre otros, desbordan los lenguajes que hasta el momento se habían construido para significar la realidad. El fuerte valor de las emociones y su rol ineludible en la formación de los imaginarios culturales contemporáneos se propone como ruta posible para discernir los nuevos contextos. De esta manera, la narrativa colombiana empieza a reconocer y problematizar los discursos y la praxis de la violencia, paulatinamente, incorpora el componente afectivo para fundar un nuevo lenguaje que descifre y visibilice la vida cotidiana en escenarios de guerra, el universo íntimo derivado de esa realidad y su potencial simbólico de la historia nefasta de una nación.

\section{NARRACIÓN DE LO ÍNTIMO Y FORMAS DE LO COLECTIVO}

El lenguaje emocional de la narrativa en cuestión expresa un pensamiento y sensibilidad social contemporánea, que recién comienza a sacar a la luz la otra cara de la guerra. Después de más de seis décadas de conflicto armado en Colombia, que ha dejado miles de civiles muertos y desaparecidos, es tan solo en las últimas décadas que se inicia en el país una progresiva valorización de la palabra de quienes lo han sufrido directamente: desplazados, hijos huérfanos, viudas, exsecuestrados, mujeres víctimas de violación, entre otros. Estas voces, poco a poco han empezado a visibilizar la realidad oculta de la violencia, sus relatos dan forma a la invisible geografía de sentimientos y emociones que surcan a las comunidades más golpeadas por la arremetida de los diversos actores armados.

La consolidación del género testimonial en Colombia, a finales de los ochenta y durante la década de los noventa, es uno de los pasos más decisivos en la reelaboración del pasado - por cercano que sea- a partir de la memoria emocional del sujeto afectado. Idóneo para indagar en temas referentes al conflicto bélico y recurrente en la narrativa de los años noventa, lo testimonial anunció cambios importantes en la concepción de la literatura (Jaramillo, Osorio y Robledo 44). Precisa Rueda, que si bien en Colombia ya se habían 
publicado testimonios sobre la Violencia ${ }^{7}$, estos aparecieron como fundamento de estudios sociológicos o históricos para mostrar las causas generales del conflicto o como ejemplo de sucesos atroces. Es a partir de mediados de la década de los ochenta que se inicia la publicación de la narrativa testimonial en el formato que prevalece actualmente, y con el objetivo de visibilizar el trauma social desde una voz personal (126-155). Es decir, que se nombraba la violencia para reconocerla como suceso histórico pero no primaba el objetivo de dar visibilidad a la víctima, cuestión que derivaba en la negación de los afectos y del sujeto en sí mismo.

Dos casos de publicaciones testimoniales, con buena recepción por parte de la crítica, son Los años del tropel: relatos de la violencia, de Alfredo Molano y Las mujeres en la guerra, de Patricia Lara. El propósito de Molano fue el de contribuir a la creación de un archivo histórico alterno, que recogiera las experiencias aún indocumentadas de gente que sufrió la Violencia de mediados de siglo XX; mientas que para Lara primó el dar voz a mujeres que sufrieron la violencia sociopolítica: viudas y madres de personas asesinadas, víctimas de secuestro o desplazamiento, excombatientes de la insurgencia armada, entre otras. La construcción de estos relatos, en primera persona, se ofrecen como umbral en el cual el dolor, el rencor, el miedo, y acaso la esperanza, coexisten y perseveran en la búsqueda de su camino hacia el reconocimiento y la representación.

Dentro del género testimonial también aparecen textos que cuentan la experiencia del secuestro, por ejemplo, Cautiva, de Clara Rojas, y No hay silencio que no termine, de Ingrid Betancourt. Todos estos testimonios tienen un carácter colectivizante, pues aunque surgen de la necesidad de narrar lo vivido, de llevar a la palabra una experiencia personal, son eco a su vez de muchas voces que se identifican con tal experiencia. La narrativa testimonial en la cual las memorias, la ficción, la entrevista y otros materiales se entrelazan, capturan una verdad -individual y colectiva- que de otra manera sería inaprehensible (Gómez y Giraldo 18-23). De esta manera, la vida emocional

Recuérdese aquí que la Violencia, con mayúscula, señala el periodo de entre mediados de la década de 1940 y comienzos de la de 1960, cuando desemboca la brutal confrontación entre miembros de los partidos políticos liberal y conservador. Según Sánchez Gómez, fue una guerra entre las clases dominantes y en cuanto tal una versión tardía de las guerras civiles decimonónicas; pero también fue una guerra entre las clases dominantes y el movimiento popular. Cabe destacar también, que el recrudecimiento de esta Violencia se desató a causa del asesinato del líder político popular Jorge Eliécer Gaitán el 9 de abril de 1948. 
derivada de situaciones de violencia toma forma; lo afectivo social se hace palpable en los relatos personales del trauma. Como recuerda Moraña en La escritura del límite, retomando a Taussing, es en esta clase de textos, en los que aflora lo íntimo, más que en la historia de la violencia y el miedo, donde puede captarse "la cualidad persistentemente irreal de la realidad" (187).

Una situación más que deseamos resaltar, porque resulta igualmente decisiva en el proceso que ha llevado la narrativa en la recuperación de la memoria emocional de la violencia, es el empoderamiento que se le ha dado a los investigadores del Centro Nacional de Memoria Histórica (CNMH). En la última década, el propósito de esta institución de indagar el impacto social de las secuelas afectivas de la guerra ha dado prioridad al relato de quienes vienen sufriendo en la propia piel la situación de violencia del país. A partir de las voces de las víctimas, lo "persistentemente irreal" de la violencia va tomando representación y sentido. Este proceso ha ido consolidándose en una serie de informes que, además de situar espacial y temporalmente cada acontecimiento de guerra, narran las vicisitudes, las impresiones y reflexiones de cada entrevistado ${ }^{8}$; particularizan a la víctima devolviéndole su papel social, su capacidad de voz y resistencia. Se testimonia la voluntad de muchos para superar el trauma. Los informes construidos desde la verdad subjetiva, trazan una memoria contundente y veraz sobre la historia social y política del país. Publicados a partir de 2008, las voces de las víctimas comienzan a dar forma a lo "fantasmagórico" de la lucha armada. La subjetividad de sus relatos es lenguaje válido para significar una realidad todavía indocumentada de la historia nacional.

Por otra parte, entendemos que las formas como actualmente la realidad caótica del país va siendo entendida y narrada es además respuesta al colapso de los discursos tradicionales que asocian la guerra y las prácticas de violencia con la construcción de nación. Las lógicas habituales que se usaban hasta hace pocas décadas para entender la praxis de la violencia han perdido credibilidad y validez (Pécaut, Mbembe). En Colombia, parte del origen de esa problemática puede situarse en la creciente vinculación del Estado en prácticas clandestinas e ilícitas, y en el cambio de estrategias de

\footnotetext{
Los informes del CNMH contienen relatos precisos de muchos ciudadanos colombianos que han sufrido los vejámenes más horrorosos a manos de los combatientes -Estado, guerrilla, narcos, paramilitares-. Se pueden consultar en el sitio web del CNMH: http://www.centrodememoriahistorica.gov.co/informes
} 
combate presentadas por los cuadros guerrilleros. Hechos como el secuestro, la extorsión, el tráfico de droga y el asesinato deliberado de civiles erosionan los principios éticos e institucionales que deben distinguir a todo tipo de gobierno. El impacto social de estas circunstancias, en efecto, se vislumbra en el conjunto de emociones que como espacio epistémico se configuran en la narrativa reciente con el objeto de descifrar el estado de cosas de un país.

Antes de cerrar este texto, queremos hacer un breve comentario sobre la fase actual de parte de la crítica literaria en Colombia. La narrativa de la violencia ha sido estudiada principalmente desde el marco de las ciencias sociales y del discurso histórico, haciéndose especial énfasis en las causas políticas y sociales de la guerra y sus efectos. Si bien se reflexiona sobre las consecuencias psicosociales de tantas décadas de conflicto son los elementos activos que lo desencadenan: los victimarios y la historia de la nación, los que concentran la atención. La metáfora del poder ha jugado el rol central al momento de relacionar las propuestas de escritura de los autores colombianos con el contexto de referencia ${ }^{9}$. Este enfoque sigue abriendo valiosos panoramas de comprensión de la sociedad nacional y motiva cuestionamientos para la exégesis de las novelas; sin embargo, consideramos que la novelística que viene descifrando los contextos de violencia a partir de lo emocional traumático reclama nuevos ángulos de interpretación. El miedo, el rencor y el sufrimiento íntimo son la contracara de la metáfora del poder, necesitan, por tanto, de una mirada crítica que los reconozca como lenguaje que articula y da representación a las realidades no siempre perceptibles de la vida social en el país.

En relación con el argumento anterior, vale citar aquí algunos estudios recientes que, aunque no se vinculan de manera directa con lo emocional,

\footnotetext{
El propósito de este ensayo se deslinda de la discusión específica en torno a la tradición de los estudios críticos en Colombia. Para profundizar en este aspecto, recomendamos las pesquisas de Jaime Alejandro Rodríguez Ruíz publicadas en su blog Novela Colombiana. Siglo XX. Novela reciente; asimismo, el monográfico Literatura colombiana entre milenios, de la Revista Literatura: teoría, historia, crítica (2012), de la Universidad Nacional de Colombia; también resulta valioso el libro producto de investigación: Hallazgos en la literatura colombiana. Balance y proyección de una década de investigaciones (2011), de Juan Alberto Blanco, Cristo Rafael Figueroa, Luz Mary Giraldo, Blanca Inés Gómez y Jaime Alejandro Rodríguez. Los libros de Oscar Osorio igualmente son referente clave en este tema: El narcotráfico en la novela colombiana (2014) y La virgen de los sicarios y la novela del sicario en Colombia (2014). Y el ya citado libro Literatura y cultura: narrativa colombiana del siglo XX (2000), de las compiladoras de Jaramillo, Osorio y Robledo.
} 
proponen otras rutas explicativas del simbolismo estético de la escritura que incorpora los conflictos nacionales. Estos estudios no siguen los enfoques tradicionalmente utilizados por la crítica literaria en Colombia. Por ejemplo, Jaramillo Morales en su libro Nación y melancolía: narrativas de la violencia en Colombia (1995-2005), relaciona novela y cine con conceptos del psicoanálisis. Esta investigación explora los modos cómo lo estético simboliza la sensibilidad melancólica, un estado psíquico-afectivo que, según la académica, definió el comportamiento social de la Colombia de finales del siglo XX. Por su parte, Rueda en La violencia y sus huellas. Una mirada desde la narrativa colombiana, propone una exégesis diferente de los estragos del conflicto armado a partir del elemento ético. La investigadora pone en el centro de la discusión "la ética del lector" para revisitar corpus narrativos de inicios de siglo XX y de textos testimoniales recientes. El debate gira en torno a conceptos como ética y violencia, términos que por su recurrencia misma se han cristalizado en su sentido y se citan en diversas reflexiones de manera impensada. Residuos de la violencia. Producción cultural colombiana, 1990-2010, de Fanta Castro, asocia la literatura con la pintura, la escultura y el cine, para explorar la dinámica simbólica de lo marginal-corpóreo en los contextos de violencia contemporánea y los procesos de subjetivación derivados de tal situación. Este tipo de trabajos son bienvenidos, ya que contribuyen, desde perspectivas, metodologías y disciplinas particulares, a una cuestión tan estimulante como es la estética de la violencia en las letras colombianas. Son pesquisas que trazan nuevas coordenadas de análisis, abren un renovado espacio de indagación, y confrontan paradigmas no solo de rasgo metodológico sino también de carácter conceptual ${ }^{10}$.

Para concluir, el enfoque socio-histórico de los estudios literarios en Colombia ha dado forma a un entramado crítico valiosísimo, productor de múltiples lecturas en torno a la tensión entre los procesos literarios nacionales y las dinámicas de la historia social y política. Sin embargo, se reconoce que ese transcurso analítico así como ha propuesto una serie de caminos significativos para ahondar en los diversos sentidos que propone lo literario,

10 Los estudios literarios desde la perspectiva de género y queer han aportado una valiosa teoría de los afectos para confrontar el racionalismo heteronormativo y analizar la construcción de masculinidades y femineidades. Hibridez y alteridades, volumen III del estudio Literatura y cultura: narrativa colombiana del siglo XX, (2000). Editado por María Mercedes Jaramillo, Betty Osorio y Ángela Inés Robledo, es una fuente importante sobre este enfoque de análisis. 
paradójicamente, también ha nublado la posibilidad de líneas de indagación desde otras ópticas. El estado actual de la crítica literaria en Colombia deja ver que hasta hace muy poco los estudios que no se alineaban a la mirada canónica quedaban al margen o pasaban inadvertidos (Suárez, Rueda). La indagación de la violencia en relación con fundamentos conceptuales del campo fenoménico, del psicoanálisis o de las diversas líneas de profundización sobre los afectos y las emociones, que proponen, por ejemplo, los estudios culturales, la crítica de género, la historia, la filosofía o la psicología, son relativamente pocos en el campo académico-literario en Colombia, en comparación con los de enfoque socio-histórico. Ante este paisaje, y las nuevas lecturas que la narrativa viene haciendo de la realidad social, es necesario abrir otras rutas de exploración que vindiquen lo emocional como vía de acceso a lo real, lo simbólico y lo imaginario de las dinámicas sociales del país.

\section{BIBLIOGRAFÍA}

Agamben, Giorgio. Lo que queda de Auschwitz. El archivo y el testigo. Homo Sacer III. Trad. Antonio Gimeno Cuspinera. Valencia: Pre-textos, 2000. 143-180.

Ahmed, Sara. La política cultural de las emociones. Trad. Cecilia Olivares Mansuy. México: Universidad Nacional Autónoma de México, 2015.

Bartra, Roger. "La batalla de las ideas y las emociones". El lenguaje de las emociones. Afecto y cultura en América Latina. Eds. Mabel Moraña e Ignacio Sánchez Prado. Madrid y Frankfurt: Iberoamericana y Vervuert, 2012. 17-36.

Blanco Puentes, Juan Alberto. "Delirio de Laura Restrepo: La orfandad -herencia- social". Memorias de las Jornadas Andinas de Literatura Latinoamericana (JALLA 2006). Bogotá: Universidad de los Andes, Universidad Nacional, Universidad Javeriana, Instituto Pensar, 2006.

Bituing, Lotte. "An Impossible Witness of the Armies". New Trends in Contemporary Latin American Narrative: Post. National Literatures and the Canon. Eds. T. R. Robbins y J. E. Gonzáles. New York: Palgrave Macmillan, 2014. 133-152.

Castellanos Moya, Horacio. Breves palabras impúdicas. Un ensayo y cuatro conferencias. San Salvador: Revuelta, 2010.

Fanta Castro, Andrea. Residuos de la violencia. Producción cultural colombiana, 1990-2010. Bogotá: Universidad del Rosario, 2015.

Fonseca, Alberto. “'Ahora nos toca a nosotros': Fantasmas y violencia en los ejércitos”. Evelio Rosero y los ciclos de la creación literaria. Eds. Felipe Gómez Gutiérrez y María del Carmen Saldarriaga. Bogotá: Pontificia Universidad Javeriana, 2017. 163-174. 
Gaitán, Jorge. "El ruido de las cosas al caer: radiografía del miedo colombiano en la generación del setenta". Actas del Cuarto Congreso CELEHIS de Literatura. 21/01/2014.http://www. mdp.edu.ar/humanidades/letras/celehis/congreso/2011/actas/ponencias/gaitanbayona.htm

Gamboa, Santiago. Plegarias nocturnas. Barcelona: Mondadori, 2009.

García Márquez, Gabriel. "Dos o tres cosas sobre 'La novela de la violencia”". La Calle, Año 2. 103 (1959): 12-13.

Gómez, Blanca Inés y Luz Mary Giraldo. "Testimonios, representaciones y literatura documental en la narrativa colombiana contemporánea 1970-2004". Hallazgos en la literatura colombiana. Balance y proyección de una década de investigaciones. Ed. Jaime Alejandro Rodríguez. Bogotá: Pontificia Universidad Javeriana, 2011. 15-28.

Herrera Zgaib, Miguel A. "Del neopresidencialismo al presidencialismo de excepción en Colombia, 2002-2010". Historia contemporánea de Colombia. Conflicto armado, régimen político y movimientos sociales. Eds. Sergio Astorga, Mario Ayala y Esteban Campos. Mendoza: CETyL, FCPyS, UNCuyo, Quelqasqa, 2012. 237-265.

Hoyos, Héctor. "Visión desafectada y resingularización del evento violento en Los ejércitos de Evelio Rosero". El lenguaje de las emociones. Afecto y cultura en América Latina. Eds. Mabel Moraña e Ignacio Sánchez Prado. Madrid y Frankfurt: Iberoamericana y Vervuert, 2012. 283-295.

Jaramillo, María Mercedes; Betty Osorio y Ángela Robledo. Literatura y cultura: narrativa colombiana del siglo XX. Bogotá: Ministerio de Cultura, 2000.

Linares, Albinson. "Entrevista a Santiago Gamboa: 'Lo más jodido es encontrarle sentido a la vida”". 06/03/2011.http://historico.prodavinci.com/2011/11/13/artes/santiago-gamboa$\% \mathrm{E} 2 \% 80 \% 9$ Clo-mas-jodido-es-encontrarle-un-sentido-a-la-vida $\%$ E2\%80\%9D/

Mbembe, Achille. "Necropolitique". Traveresées, diasporas, modernités, Raisons politiques, 21 (2006): 29-60.

Montoya, Pablo. Los derrotados. Medellín: Sílaba, 2012.

Morales, Alejandra Jaramillo. Nación y melancolía: narrativas de la violencia en Colombia (1995-2005). Bogotá: Alcaldía Mayor de Bogotá D.C. Instituto Distrital de Cultura y Turismo-gerencia de Literatura, 2006.

Moraña, Mabel. La escritura del limite. Madrid y Frankfurt: Iberoamericana y Vervuert, 2011.

Moraña, Mabel e Ignacio Sánchez Prado (Eds.). El lenguaje de las emociones. Afecto y cultura en América Latina. Madrid y Frankfurt: Iberoamericana y Vervuert, 2012.

Nussbaum, Martha. Emociones políticas. ¿Por qué el amor es importante para la justicia? Trad. Albino Santos Mosquera. Barcelona: Paidós, 2014.

Padilla Chasing, Iván Vicente. “'Los ejércitos': Novela del miedo, la incertidumbre y la desesperanza". Literatura: teoría, historia, crítica 15. 1 (2012): 121-158.

Pécaut, Daniel. "De la violencia banalizada al terror: el caso colombiano". Revista Controversia 171 (1997): 9-31.

Restrepo, Laura. Delirio. Bogotá: Alfaguara, 2004.

Rosero, Evelio. Los ejércitos. Barcelona: Tusquets, 2006.

Rotker, Susana. Ciudadanías del miedo. Caracas: Nueva Sociedad, 2000. 
Rueda, María Elena. La violencia y sus huellas. Una mirada desde la narrativa colombiana. Madrid y Frankfurt: Iberoamericana y Vervuert, 2011.

Sánchez Gómez, Gonzalo. Guerra y politica en la sociedad colombiana. Bogotá: Punto de lectura, 2008.

Sánchez Lopera, Alejandro. "Surcar la moral. Delirio de Laura Restrepo". Revista de Estudios de Literatura Colombiana 34 (2014): 63-80.

Sofsky, Wolfgang. Tratado sobre la Violencia. Trad. Joaquín Chamorro Mielke. Madrid: Abada, 2006.

Suárez, Juana. Sitios de contienda. Producción cultural colombiana y el discurso de la violencia. Madrid y Frankfurt: Iberoamericana y Vervuert, 2010.

Van Der Linde, Carlos-Germán "Erotismo, obscenidad y abyección de Ismael Pasos en Los ejércitos". Evelio Rosero y los ciclos de la creación literaria. Eds. Felipe Gómez Gutiérrez y María del Carmen Saldarriaga. Bogotá: Pontificia Universidad Javeriana, 2017. 175-192.

Vanegas, Orfa Kelita. "Fotografía y literatura: Dimensión visual de la violencia del narcotráfico en Colombia". Periferias de la narcocracia. Ensayos sobre narrativas contemporáneas. Ed. Cecilia López. Buenos Aires: Corregidor, 2015. 163-187.

Vásquez, Juan Gabriel. El ruido de las cosas al caer. Bogotá: Alfaguara, 2011. 